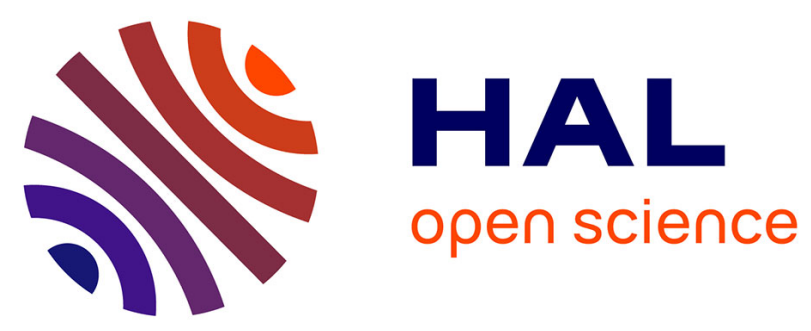

\title{
Using Disruptive Technologies in Government: Identification of Research and Training Needs
}

Alexander Ronzhyn, Maria A. Wimmer, Vera Spitzer, Gabriela Viale Pereira, Charalampos Alexopoulos

\section{To cite this version:}

Alexander Ronzhyn, Maria A. Wimmer, Vera Spitzer, Gabriela Viale Pereira, Charalampos Alexopoulos. Using Disruptive Technologies in Government: Identification of Research and Training Needs. 18th International Conference on Electronic Government (EGOV), Sep 2019, San Benedetto del Tronto, Italy. pp.276-287, 10.1007/978-3-030-27325-5_21 . hal-02445814

\section{HAL Id: hal-02445814 \\ https://hal.inria.fr/hal-02445814}

Submitted on 20 Jan 2020

HAL is a multi-disciplinary open access archive for the deposit and dissemination of scientific research documents, whether they are published or not. The documents may come from teaching and research institutions in France or abroad, or from public or private research centers.
L'archive ouverte pluridisciplinaire HAL, est destinée au dépôt et à la diffusion de documents scientifiques de niveau recherche, publiés ou non, émanant des établissements d'enseignement et de recherche français ou étrangers, des laboratoires publics ou privés.

\section{(c)(1)}

Distributed under a Creative Commons Attribution| 4.0 International License 


\title{
Using Disruptive Technologies in Government: Identification of Research and Training Needs
}

\author{
Alexander Ronzhyn ${ }^{10000-0003-3108-0405]}{ }^{\square}$, Maria A. Wimmer ${ }^{1}$, Vera Spitzer ${ }^{1}$, Gabriela \\ Viale Pereira $^{2}$, Charalampos Alexopoulos ${ }^{3[0000-0002-6610-0675] ~}$ \\ ${ }^{1}$ University of Koblenz-Landau, Institute for IS Research, Koblenz, Germany \\ \{ronzhyn, wimmer, vesp91\}@uni-koblenz.de \\ ${ }^{2}$ Danube University Krems, Department for E-Governance and Administration, Krems, Austria \\ gabriela.viale-pereiraldonau-uni.ac.at \\ ${ }^{3}$ University of the Aegean, Dept. Information and Communication Systems Engineering, Sa- \\ mos, Greece \\ alexop@aegean.gr
}

\begin{abstract}
Over the past years, a number of new technologies have emerged with a potential to disrupt many spheres of the society. While public sector traditionally lacks behind business in innovation, significant changes are anticipated with the use of disruptive technologies. The implementation of the new technologies for the government service provision, along with possible benefits, need to be well thought through and challenges need to be carefully discussed, analysed and evaluated. This paper uses scenario-technique to identify research and training needs for the implementation of disruptive technologies in government services. Using the input of 58 experts from three workshops, research and training needs for the internet of things, artificial intelligence, virtual and augmented reality, as well as big data technologies have been identified. The identified needs can serve as a starting point for a broader and more informed discussion about the knowledge and skills that the researchers and practitioners of digital government need to obtain for the broad use of such new (disruptive) technologies.
\end{abstract}

Keywords: digital government, disruptive technologies, research needs, training needs, scenario-technique

\section{$1 \quad$ Introduction}

Digital government refers to the use of information and communication technologies (ICT) for the provision of public services with the aim of increased efficiency, effectiveness and improved quality of services for the citizens $[1,2]$. Over time, along with the changes in the expectations and needs of citizens and the increasing ubiquity of technology in societies, digital government services have also been changing.

The changes in the way the public services are provided can be used as an evidence for identifying distinct stages of digital government evolution [3, 4]. The increase in participatory services and social media use by the public bodies parallel to the emergence of Web 2.0, allowed speaking of Government 2.0 or participatory government 
[5, 6]. In a different classification of phases, Janowski [7] suggested that digital government evolution can be delimited into four stages based on how government is transformed by the ICT. Broadly speaking, Janowski's third stage "Engagement or Electronic Governance" corresponds to the Government 2.0, characterized by increased participation and engagement, trust building and focus on transparency and accountability [7].

Lachana et al argue that the recent changes in the technologies used and the focus of the use of these technologies allow identifying a new stage in digital government Government 3.0 [8]. This new stage is characterized by the extensive use of disruptive technologies for provision of customized services and data-driven evidence-based decision making [9]. The term "disruptive technology" refers to the technologies, whose application has potential to drastically alter the processes and operations in a particular field of the public sector [10]. Artificial intelligence (AI), Internet of things (IoT), natural language processing (NLP), Virtual and Augmented reality (VR, AR), big data and block chain are such examples of technologies [9].

Government 3.0, as defined above, largely corresponds to the fourth stage of Janowski's [7] classification: "Contextualization or Policy-Driven Electronic Governance", which emphasizes the contextualization of the digital government efforts. This technological and thematic shift poses ethical and research challenges [11] and creates new research and training needs. The current research is a part of the Gov 3.0 project [12] that is concerned with establishing Government 3.0 as a research domain and creating a Master curriculum addressing the needs of this new stage. The current paper describes the first steps of identification of these needs using the future scenario research technique [13]. The identified needs will serve as a basis for the Government 3.0 roadmap and later the Master-level education curriculum, developed during the subsequent work packages within the project.

In the context of the paper, a "research need" is a gap identified by relevant stakeholders as important and if addressed will help to resolve a specific real-world problem [14]. A "training need" is a gap in the existing training curricula (either formal or vocational), which when addressed allows the recipients of training to manage effectively a specific real-world problem. A "problem" in both of the definitions refers to the implementation of the disruptive technology in public service as illustrated in the scenarios.

The remainder of the paper is structured as follows. Section 2 details the methodology used for collecting input from the experts in the workshop setting. Section 3 provides an example of a scenario used (3.1) and details the findings related to the research (3.2) and training (3.3) needs. Section 4 synthesises the findings and details the conclusions, suggesting directions for the future research.

\section{Methodology}

The use of future scenarios is an established method for research of possible futures in various fields, both public and private $[15,16]$. Scenarios typically describe possible 
future developments in a specific area [17], detailing the involvement of various stakeholders and interplay between these stakeholders [18]. The aim of the scenario use is to look at the problem from different viewpoints and better understand possible future evolution directions [19], thus improving decision making [20]. In contrast to forecasts and prognoses, the goal of the scenarios is to suggest several possible developments with varying degree of probability, rather than identifying the most probable future.[21, 22].

The research is guided by the following two questions:

1. What are the research needs regarding the implementation of disruptive technologies in digital government?

2. What are the training needs connected to the implementation of disruptive technologies in digital government?

In this research, we use scenario methodology as described in Ronzhyn et al. [13]. First, future scenarios describing the use of the disruptive technologies were developed by the research team. These scenarios were consequently presented to the experts at the workshops to elicit input about possible research and training needs for the implementation of the scenario. The workshops were organized within one or two conference sessions and include: a) introduction to the overall task, b) scenario introduction, c) group discussion of the individual scenarios led by group moderators (addressing both, research and training needs, and prioritising these needs), and d) summary of the workshop with brief discussion of the scenarios by all the participants. As a result of the discussion, experts provide a list of research and training needs along with the assessment of how important or pressing a particular need is. The assessment is a result of the expert consensus within a group. For prioritisation a three-level system is used: green - low importance, yellow - medium importance, and red - high importance.

Three workshops were organized to collect input from the experts in the field of digital government: the Roadmapping workshop at Samos Summit (Samos, Greece) in July 2018, the Roadmapping workshop at the EGOV-CeDEM-ePart 2018 conference (Krems a.d. Donau, Austria) in September 2018 and the Workshop at the NEGZ: Herbsttagung Conference (Berlin, Germany) in November 2018. In total seven different scenarios were discussed (some of them at more than one workshop). Scenarios included possible future implementations of AI, ML, NLP, IoT, AR, VR and Blockchain technologies as well as implementations of the broader concepts of smart city, gamification and co-creation of public services. Most of the scenarios involved more than one technology. For example, one of the scenarios described the use of crowdsourced sensors to monitor air quality in cities (IoT, smart city) and automated decision making to make sense of the collected data (ML, AI). A different scenario described an example of implementation of gamification of social services based on the AR technology. A total of 58 experts participated in workshops, among them academics, public officials, government representatives and private sector representatives. Experts involved were also rather varied geographically: the majority of participants came from European organizations; several participants came also from the Americas, Asia and Australia. The diversity among experts allowed gathering diverse and original input based on experts' individual backgrounds and experiences. 
62 distinct research needs, and 54 trainings needs were collected, and additional notes by workshop moderators were taken along the discussions and used in the analysis to better understand the suggested needs. The prioritisation of the needs was done by the experts in the workshop, however, if a specific need was prioritized differently by different groups in distinct workshops, then an average prioritisation was given to the need. The needs have been classified into categories based on the area of concern (6 research and 5 training need categories, see sections 3.2 and 3.3). The classification was done by four researchers of the project employing an inductive method (described e.g. in [35]).

\section{$3 \quad$ Findings}

Below, one of the scenarios is introduced along with a poster as an example of how the use of a disruptive technology in public service was presented during the workshop. Subsequently, in 3.2 and 3.3 the results of the workshops are described together with the categories that emerged during analysis.

\subsection{Scenario example}

The example scenario "Intelligent citizen portals connected across Europe using chatbot interface for easy interaction with citizens" details a possible use of AI and machine learning coupled with natural language processing technology, realizing a chatbot interface for better cross-border public services. Figure 2 provides a brief textual description of the scenario - a more detailed version was presented to the workshop participants.

Relocating to another country or similar action involving two or more different countries often carry high administrative burden. Citizens not only have to organize many documents over a short period of time, but also have to consider the different regulations of their home vs. destination country. In the future, the use of intelligent citizen portals with chatbot interface simplifies the organisation of complicated procedures involving authorities in multiple countries. A citizen uses a smartphone to contact the government chatbot and requests help with the process. The citizen can send messages written in natural language without the need to use specific commands. A chatbot then processes the text using Natural Language Processing and AI to understand the meaning of the request and provides relevant answer. In a further future, a chatbot can even process the voice commands and provide answers.

The chatbot acts as an interface connecting a citizen to the intelligent portal. The portal is designed in a way to interoperate with other portals and databases across Europe. If eID is used by the citizen, the portal application can then use it to access the relevant information across borders (according to the Once-Only Principle ${ }^{1}$ ). The application can also identify the missing information required for the relocation of the citizen and ask necessary questions to gather this information. Furthermore, the intelligent portal can automatically complete foreign forms and help with understanding the specific terms, providing assistance through the conversation with a chatbot.

\footnotetext{
${ }^{1}$ https://ec.europa.eu/digital-single-market/en/european-egovernment-action-plan-2016-2020
} 
Based on the Once-only principle, AI, NLP and the intelligent citizen portal, relocating abroad (and other similar cross-border formalities) is no longer a complicated matter for the citizen and for public authorities.

Figure 1. Short description of the "Intelligent Portals" scenario

As described in the methodology, the scenario provides an example of possible future implementations of disruptive technologies in public service provision. While most of the relevant technologies can be implemented practically even today, some parts depicted in the scenario are still not quite ready (for example OOP has not been fully implemented across European borders and interoperability between different public organization is still a challenge; even more so between public and private organizations).

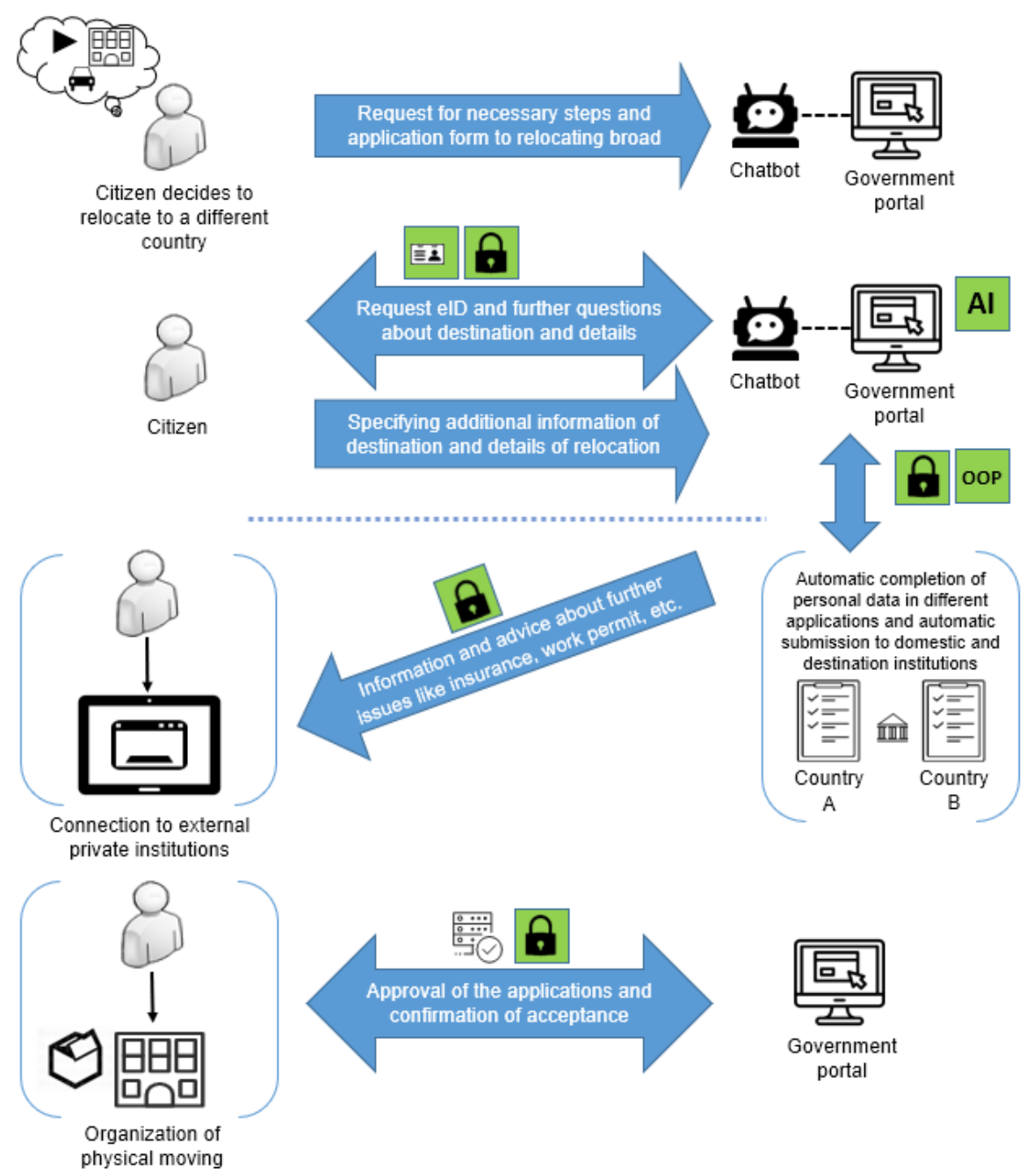

Figure 2. Scenario poster - "Intelligent citizen portals connected across Europe using chatbot interface for easy interaction with citizens" 
The poster used along with this scenario is shown on Figure 2. On the poster, the arrows represent the exchange of information between the actors, while the boxes show technological enablers that are involved at each of the steps for information processing (e.g., AI system) and for information exchange (e.g., encryption). Both artefacts were used to deliberate research and training needs with the experts in the different workshops. The subsequent descriptions outline the main research and training needs identified during the workshops.

\subsection{Research needs}

\subsubsection{Standardisation and Interoperability of disruptive technologies}

Standardisation includes the needs for further research of possible standards for the disruptive technology implementation: standards for the use of AI for automated decision making, standardisation of collected data by IoT and the standardisation of the IoT devices. Common standards are especially important in IoT as different models of sensors can be used as a network to provide valuable results, so the data collected by these sensors needs to be compatible and interoperable.

Linked to standardisation, interoperability research needs deal with ensuring that different implementations of the same technology are able to effectively "talk to each other". These needs are of high priority both in IoT (especially technical interoperability of different sensors [23]) and in AI/ML research (in the intelligent portals scenario, where cross-border interoperability is a necessity).

\subsubsection{Analysis of stakeholders}

This category describes the engagement of stakeholders in the implementation of modern technologies as a fundamental requirement for successful implementation and use of these technologies. Stakeholders are those who affect or are affected by decisions or actions [24]. In the implementation of disruptive technologies, it is necessary to understand who the stakeholders are, how to engage various stakeholders effectively and identify the needs of target groups to involve them adequately in the implementation process. Technologies like Blockchain, AI and Machine Learning have been the biggest research needs in stakeholder (citizen) engagement, co-creation and improvement of already existing solutions both in public and private sectors. Further research needs include the user studies comparing the use of traditional web search functions and modern solutions such as Chatbots. How far can a Chatbot based on AI and ML take over the functions of traditional web and how can the digital divide between different user groups be overcome in the future, with the use of AI-driven technologies? Another research need arises as to whether citizen engagement/ co-creation and outsourcing to the private sector could increase the acceptance of and trust towards IoT, AI and ML systems. Similarly, it is necessary to examine existing architectures of technologies for their suitability in the public sector. 


\subsubsection{Evaluation and Policy making}

The category refers to the necessity of assessment of impact and costs of the disruptive technologies' implementation. The research needs of the present category were raised when discussing AI (adapting legislation to the use of cross-border data) and IoT (automated policy making based on IoT data). Further research is necessary to identify the ways to adapt legislation for effective implementation of some technologies in public sector (like video monitoring regulation for $\mathrm{AI} / \mathrm{ML}$ ) and the implications of using $\mathrm{AI}$ for the creation of regulations and policy (e.g., exploring the dangers of bias in ML [25, 26]).

The proper way of using simulation and data modelling for e-government services is another research need. Simulation can be used for policy modelling in different settings and in the design of predictive models. In both cases it may be used as a basis for data-driven decision making. The issues of accuracy of data and accountability need to be addressed when using simulation and data modelling for making decisions.

Research needs of this category are often transdisciplinary and also very much dependent on the field where the technology is to be used. For different scenarios involving IoT, research needs may include research of urban environment (when IoT are implemented as a part of a Smart City imitative) or "earth/water evaluation" (when IoT sensors are used in agriculture).

\subsubsection{Data security and Data privacy}

Data security and data privacy are two important topics for research of the use of disruptive technologies in public sector. The willingness to allow collection, sharing and the use of sensitive citizen data is contingent on high trust in these technologies and administrations deploying them. In particular, the security and privacy of the Blockchain technology need to be addressed in the context of public service. While implemented private-sector solutions (e.g. in finance) are being used and further developed, the potential for the use of Blockchain in the public sector needs to be researched and evaluated further in the context of e-government [27] while most of the papers tend to focus on benefits of the technology rather than possible challenges of its implementation [28]. Privacy and security issues need to be researched in the context of storing sensitive personal data and allowing specific actors the access to these data [29].

Data privacy is a significant issue in IoT as well, especially in urban setting. In case studies [30], data privacy and security were found to be the main impediments on the strategic level for the introduction of IoT for e-government. Data accuracy is another issue critical for the implementation of IoT in smart cities. Research needs in data quality are connected to the standardization issues described in 3.2.1.

\subsubsection{Automated decision-making}

Due to the digitization of the public sector processes, the use of modern technologies and automation mechanisms is indispensable. Thus, the possibilities of using disruptive technologies and their possible effects must be investigated. The big data collected by 
sensors can be automatically processed and analyzed using the AI and ML technologies to provide real-time decisions. Such system may offer significant advantages over "manual" regulation and improve the quality of life in cities [31], yet it poses a number of challenges concerning transparency and accountability. There are also concerns related to adaptability of such systems: as different environments offer different challenges, there might be no one standard way of organizing automated decision-making based on the collected environment data. Further case-study research is necessary to see how AI and ML may be adapted on the local level [32].

The use of autonomous agents also poses a concern related to the inclusivity and trust. Further research on the integration of autonomous systems in public services is necessary: addressing both the technological issues (design of such agents) and behavioral issues (public perception of the agents).

The challenges of implementation of VR and AR in the public sector reveal further research needs. In particular, the possibilities and benefits of VR and AR in connection with smart buildings must be examined in more detail. Also in regard to the training needs, further research is needed on the benefits of gamification methodology in the VR and AR contexts.

\subsubsection{Ethical issues}

A common research need in the discussion of the disruptive technologies is ethics and moral issues. By far, AI is the most ethically controversial technology. Research directions regarding AI include privacy research (surveillance, profiling), ethics of automated decision making (especially concerning sensitive decisions, e.g., in law enforcement, health), issues of responsible research. The discrepancies between the real world and the data used for AI-based decision making was identified as a high-priority research issue as decisions based on incomplete (or even biased) information may be unfair and problematic. One of the ethical issues raised in regard to the implementation of IoT is the sustainability of sensors infrastructure; if IoT sensors are used in rural environments, they are much more difficult to control and recycle properly. Possible pollution is an ethical concern that needs to be researched. An earlier study [11] showed that there is significant number of ethical issues connected to implementation of disruptive technologies in public service.

\subsection{Training needs}

\subsubsection{Technology}

AI and Machine Learning, Blockchain and IoT are the technologies with most technical requirements for using and implementing them in public sector. When using $\mathrm{AI} / \mathrm{ML}$, field experts in multidisciplinary domains are required to have expertise in modelling and tools, which requires professional training. Public officials must be able to deal with non-standard situations in requests through digital agents and addressing multiple identities in the system. For the implementation of these technologies, skills on app development, security encryption and access rights are fundamental. For implementing blockchain technical training of identity providers, employers, public sector and social 
workers is necessary, as well as the understanding the impact of decentralized distributed system on current administrative processes. Public officials training on the use of specific devices are important for the use of VR/AR equipment and IoT sensors. Implementing IoT also requires skills on decision system modelling, monitoring systems and fog computing/infrastructure.

\subsubsection{Management}

Management training is found to be relevant for applying AI/ML, Blockchain and IoT in public sector. Considering AI/ML applications, relevant aspects include the ability to involve citizens in the process, as well as knowledge management and business models of social work (social innovation). Training on process/change management is important for using VR/AR in government. Similarly, IoT applications require courses for public employees on project management, entrepreneurship, doing business and costbenefit analysis.

\subsubsection{New technologies in Public Management \& E-Government}

Training on public management and e-government is important for applying most of the discussed disruptive technologies such as AI/ML, Blockchain and IoT. For government employees using AI/ML, skills on new technical components (IT systems) and new legal basis are required, as well as the ability to establish a framework for cooperation with private companies. For blockchain, including a basic training for public sector specialists on the technology use in government is required. When using IoT in government applications, training needs refer to introductory topics of e-government such as enterprise architecture, public administration and public sector innovation, as well as the emergent digital transformation domain, which refers to complete redesigning of the government services to fulfil changing user needs [33].

In addition to the major training needs of this category, our research indicates the lack of soft skills mainly for the public officials and citizens regarding acceptance of disruptive technologies such as AI and blockchain. A "train the trainers" approach seems to be the most efficient one for covering this need.

\subsubsection{Data Science \& Data security}

Most of the training needs concerning data science and security are connected to the implementation and use of the AI, ML and IoT technologies. It is worth mentioning that these 3 technologies have been used in different tested scenarios (except 3 and 6). Our results reveal lack of knowledge on data analysis and artificial intelligence tools, the ways of achieving data trust and security including accuracy of the IoT devices and user input for the target groups of civil servants, professionals and citizens. Legal issues training is identified as a very important training need for all target groups including researchers, especially concerning the blockchain and AI technologies. 


\subsubsection{Responsibility \& Sustainability}

The last category of the identified training needs has to do with responsible research and sustainability of the applied solutions. Again, in regard to AI, a need to train the researchers in ethics was identified, specifically concerning the ethical solutions to the problems of automated decision-making. For public servants, the focus is on the managerial training needs: sustainability assessment of the applied solutions (IoT) in the public sector understanding what technology should be applied and if this technology is covering the current needs.

\section{Discussion and Conclusions}

The number and diversity of identified research needs is rather high, reflecting the novelty of application of the disruptive technologies for public service provisioning. First, researchers need to carefully examine the necessity for the implementation of services based on these technologies: evaluate the advantages (or disadvantages), which the new technology will bring in the specific cases. Then, there are research needs regarding the effective and ethical use of the data collected and its use for decision making. The critical issues of privacy and security have to be addressed to ensure the responsible implementation of such services and their acceptance by the public. Finally, as many public services are not limited to one country, research and development of standards is important to ensure interoperability of services.

Many of the research needs discussed in this paper have already been mentioned by the researchers of the specific technologies: for IoT in public services, interoperability and standardisation are seen as a major issues [34], in the AI research, ethics has been a steady concern [35] and privacy is a huge pressing issue in ICT generally [36] and with the implementation of the once-only principle. The research needs highlighted in the context of disruptive technologies in public service shall stimulate the discussion and help to further advance the digital government research and practice.

The analysis of training needs reveals two types of training that are needed. For the academics and professionals who are going to implement the new services, training in the technology is necessary: both general training regarding data security, privacy and sustainability, and specific training on particular technologies. At the same time, for public officials, soft and managerial skills training is particularly important for ensuring citizen trust towards the disruptive technologies. Services based on these technologies are significantly different from the ones of the current generation and acceptance of the new services by the public is a critical issue. In this regard, training the trainers (public officials, administrators) is the critical need so that stakeholders are able to use the new technologies and explain the benefits and functionality to the public.

Involving experts in the discussion of the new technologies in public services is very important. The chosen scenario-based technique has shown good results in stimulating the discussion and gathering diverse insights on disruptive technologies in digital government. Still, the workshop-based scenario approach has some limitations that need to be acknowledged: First, the competence area of an expert has an effect on the type of 
suggested needs. Experts from public service tend to view problems from the perspective of a government employee, while people with background in informatics are more interested in issues connected to the technical realisation and data. This means that if a particular discussion group at the workshop lacked experts from the scenario's field, the importance of some of the research and training needs was conceivably underestimated. Policy makers (largely absent from the workshops) could provide a unique vantage point and new useful needs. The second limitation of the approach is that it does not produce 'ready' research and training needs, and the experts need to be involved after the workshops, at the stage of analysis, to refine the participants' contributions and draw useful conclusions.

As stated in the Introduction, this paper does not aim to provide an exhaustive list of research and trainings needs. Instead, the goal is to specify a starting point for a broader discussion of the necessity to address some issues that arise as the result of implementation of disruptive technologies in digital government. An example of such an issue to be addressed is the negative consequences of the disruptive technologies, which can be the topic of the future research.

The research within the project will continue to further develop the findings described in this paper and to produce useful recommendations regarding the implementation of disruptive technologies in public service. The insight gained through the scenario-based workshops and described in this paper will be used further within the Gov 3.0 project [37]. First, in the elaboration of the Government 3.0 research roadmap and, secondly, for the development of the joint Master curriculum, addressing the identified training needs.

\section{References}

1. Yildiz, M.: E-government research: Reviewing the literature, limitations, and ways forward. Gov. Inf. Q. 24, 646-665 (2007).

2. Brown, M., Brudney, J.: Achieving advanced electronic government services: An examination of obstacles and implications from an international perspective. In: Proceedings of the Sixth National Public Management Research Conference (2001).

3. Mukabeta Maumbe, B., Owei, V., Alexander, H.: Questioning the pace and pathway of e-government development in Africa: A case study of South Africa's Cape Gateway project. Gov. Inf. Q. (2008).

4. Baumgarten, J., Chui, M.: E-government 2.0. McKinsey Q. 4. 2, 26-31 (2009).

5. Bonsón, E., Torres, L., Royo, S., Flores, F.: Local e-government 2.0: Social media and corporate transparency in municipalities. Gov. Inf. Q. 29, 123-132 (2012).

6. Baumgarten, J., Chui, M.: E-government 2.0. McKinsey Q. (2009).

7. Janowski, T.: Digital government evolution: From transformation to contextualization. Gov. Inf. Q. 32, 221-236 (2015).

8. Lachana, Z., Alexopoulos, C., Loukis, E., Charalabidis, Y.: Identifying the Different Generations of Egovernment: an Analysis Framework. In: The 12th Mediterranean Conference on Information Systems (MCIS). pp. 1-13. , Corfu, Greece (2018).

9. Pereira, G.V., Charalabidis, Y., Alexopoulos, C., Mureddu, F., Parycek, P., Ronzhyn, 
A., Sarantis, D., Flak, L., Wimmer, M.A.: Scientific foundations training and entrepreneurship activities in the domain of ICT-enabled governance. In: Proceedings of the 19th Annual International Conference on Digital Government Research Governance in the Data Age - dgo '18. pp. 1-2. ACM Press, New York, New York, USA (2018).

10. Kostoff, R.N., Boylan, R., Simons, G.R.: Disruptive technology roadmaps. Technol. Forecast. Soc. Change. (2004).

11. Ronzhyn, A., Wimmer, M.A.: Literature Review of Ethical Concerns in the Use of Disruptive Technologies in Government 3.0. In: ICDS 2019: The Thirteenth International Conference on Digital Society and eGovernments. pp. 85-92. IARIA, Athens (2019).

12. Gov 3.0: Gov 3.0 - Scientific foundations training and entrepreneurship activities in the domain of ICT - enabled Governance, https://www.gov30.eu/.

13. Ronzhyn, A., Spitzer, V., Wimmer, M.A.: Scenario Technique to Elicit Research and Training Needs in Digital Government Employing Disruptive Technologies. In: Proceedings of dg.o 2019: 20th Annual International Conference on Digital Government Research (dg.o 2019), June 18, 2019, Dubai, United Arab Emirates. ACM, New York (2019).

14. Chang, S.M., Carey, T.S., Kato, E.U., Guise, J.M., Sanders, G.D.: Identifying research needs for improving health care. Ann. Intern. Med. (2012).

15. Ratcliffe, J.: Scenario building: a suitable method for strategic property planning? Prop. Manag. 18, 127-144 (2000).

16. Schwartz, P.: The art of the long view: Planning for the future in an uncertain world. (1996).

17. Johnson, K.A., Dana, G., Jordan, N.R., Draeger, K.J., Kapuscinski, A., Schmitt Olabisi, L.K., Reich, P.B.: Using participatory scenarios to stimulate social learning for collaborative sustainable development. Ecol. Soc. 17, (2012).

18. Carroll, J.M.: Five Reasons for Scenario-Based Design. In: Proceedings of the 32nd Hawaii International Conference onsystem Sciences. pp. 1-11 (1999).

19. Janssen, M., Van Der Duin, P., Wagenaar, R.W., Dawes, S., Bicking, M., Wimmer, M.A., Petrauskas, R.: Scenario building for E-Government in 2020: Consolidating the results from regional workshops. Proc. Annu. Hawaii Int. Conf. Syst. Sci. 296-297 (2007).

20. Ringland, G.G.: Scenarios in Public Policy. Wiley, Chichester, UK (2002).

21. Peterson, G.D., Cumming, G.S., Carpenter, S.R.: Scenario Planning: a Tool for Conservation in an Uncertain World. Conserv. Biol. 17, 358-366 (2003).

22. Bohensky, E.L., Reyers, B., Van Jaarsveld, A.S.: Conservation in Practice: Future Ecosystem Services in a Southern African River Basin: a Scenario Planning Approach to Uncertainty. Conserv. Biol. 20, 1051-1061 (2006).

23. Khan, Z., Kiani, S.L.: A Cloud-Based Architecture for Citizen Services in Smart Cities. In: 2012 IEEE Fifth International Conference on Utility and Cloud Computing. pp. 315320. IEEE (2012).

24. Freeman, E.R.: Strategic Management: a Stakeholder Approach. Pitman, New York (1984).

25. Baeza-Yates, R.: Data and algorithmic bias in the web. In: Proceedings of the 8th ACM 
Conference on Web Science - WebSci '16. pp. 1-1. ACM Press, New York, New York, USA (2016).

26. Yapo, A., Weiss, J.: Ethical Implications of Bias in Machine Learning. In: Proceedings of the 51st Hawaii International Conference on System Sciences. pp. 5365-5372 (2018).

27. Ølnes, S.: Beyond Bitcoin Enabling Smart Government Using Blockchain Technology. In: Lecture Notes in Computer Science (including subseries Lecture Notes in Artificial Intelligence and Lecture Notes in Bioinformatics). pp. 253-264 (2016).

28. Ølnes, S., Ubacht, J., Janssen, M.: Blockchain in government: Benefits and implications of distributed ledger technology for information sharing. Gov. Inf. Q. 34, 355-364 (2017).

29. Jun, M.: Blockchain government - a next form of infrastructure for the twenty-first century. J. Open Innov. Technol. Mark. Complex. 4, (2018).

30. Brous, P., Janssen, M.: A Systematic Review of Impediments Blocking Internet of Things Adoption by Governments. In: Janssen, M., Mäntymäki, M., Hidders, J., Klievink, B., Lamersdorf, W., van Loenen, B., and Zuiderwijk, A. (eds.) Lecture Notes in Computer Science. pp. 81-94. Springer International Publishing, Cham (2015).

31. Song, T., Cai, J., Chahine, T., Li, L.: Towards Smart Cities by Internet of Things (IoT) a Silent Revolution in China. J. Knowl. Econ. 1-17 (2017).

32. Zanella, A., Bui, N., Castellani, A., Vangelista, L., Zorzi, M.: Internet of things for smart cities. IEEE Internet Things J. 1, 22-32 (2014).

33. Mergel, I., Kattel, R., Lember, V., McBride, K.: Citizen-oriented digital transformation in the public sector. In: Proceedings of the 19th Annual International Conference on Digital Government Research Governance in the Data Age - dgo '18. pp. 1-3. ACM Press, New York, New York, USA (2018).

34. Ahlgren, B., Hidell, M., Ngai, E.C.H.: Internet of Things for Smart Cities: Interoperability and Open Data. IEEE Internet Comput. (2016).

35. Dameski, A.: A Comprehensive Ethical Framework for AI Entities: Foundations. In: Iklé, M., Franz, A., Rzepka, R., and Goertzel, B. (eds.) Artificial General Intelligence. pp. 42-51 (2018).

36. Smith, H.J., Dinev, T., Xu, H.: Information Privacy Research: An Interdisciplinary Review. MIS Q. 35, 989-1015 (2011).

37. Gov 3.0: Gov 3.0 - Scientific foundations training and entrepreneurship activities in the domain of ICT - enabled Governance, https://www.gov30.eu/. 